\title{
Differential effects of graduating during a recession across gender and race
}

Ayako Kondo

Correspondence: akondo@ynu.ac.jp Yokohama National University, Yokohama, Japan

\begin{abstract}
This study examines the differential effects of the unemployment rate at labor market entry, defined as the time of leaving school, on subsequent wages across gender and race using the National Longitudinal Survey of Youth 79. Results suggest that the negative effect of a recession at entry on wages is weaker for women. The differences between blacks and whites are not statistically significant for both genders. These results are robust to controlling for the endogenous timing and location of entry, using an instrumental variable based on the predicted year of graduation and the state of residence at age 14 .

JEL codes: J01, J14, J16.

Keywords: Gender, Race, Recession at entry
\end{abstract}

\section{Introduction}

Recent studies have established that entering the labor market during a recession has long-term negative effects on subsequent wages and career paths for white male college graduates (Genda et al. 2010; Kahn 2010; Oreopoulos et al. 2012). It is also known that, in the United Sates, the initial impact of a recession at entry on earnings immediately after graduation is stronger for high school graduates than for college graduates, but this negative effect diminishes quickly (Genda et al. 2010; Speer 2015). However, there is limited evidence regarding the long-term consequences of shocks at entry for women, and similar evidence for any racial minority is even scarcer. Compared to white men, women have a weaker attachment to the labor force, and blacks are more vulnerable to contemporaneous labor market conditions. Therefore, the effects of the early labor market experience may be quite different for women and blacks than for white men.

Economic theories predict that the negative effect of a recession at entry to the labor market on subsequent wages is more persistent for demographic groups who have strong labor force attachment and are less likely to be dismissed. This is because the advantage of obtaining a high-wage job at entry is lost when the worker quits due to exogenous reasons or is dismissed. Since women are more likely to quit for family reasons, the negative effect of a recession at entry is expected to be weaker and less persistent for women than for men. In addition, since blacks are more likely to become unemployed in recessions after entry, ${ }^{1}$ the negative effect of entering the labor market 
during such periods may be less persistent for them, although the initial impact of a recession is expected to be stronger.

Motivated by these theoretical predictions, I examine how the effect of the unemployment rate at entry to the labor market on subsequent wages differs across race and gender. Specifically, I compare the effect for the following four demographic groups: white men, white women, black men, and black women. The main data source is the National Longitudinal Survey of Youth 79 (NLSY79). To control for nation-wide cohort effects, I exploit variations in unemployment rates across states, with controls for state-fixed effects. I also address the endogenous determination of time and location of entry by using an instrumental variable based on the predicted timing of entry and the state of residence at age $14 .^{2}$ I find a weaker effect of a recession at entry for women than for men. However, I do not find strong evidence for the differential effect across race.

To the best of my knowledge, this is the first study to analyze the differential effect of labor market conditions at entry across race. However, it is not the first study to examine the effect of labor market conditions experienced at youth for women. ${ }^{3}$ Hershbein (2012) compares high school-educated men and women in the United States. He finds that the long-term effects of graduating high school in a recession on wages are minimal for women and that young women who face adverse labor market conditions temporarily reduce labor supply and substitute into home production. ${ }^{4}$ I believe this study complements that of Hershbein (2012) because my approach is different from his. First, while Hershbein (2012) focuses on the effect of the unemployment rate at high school graduation for all individuals including those who proceed to college, I focus on the effect of the unemployment rate in the last year of enrollment. Furthermore, I measure differences across and within racial groups. In addition, methodologically, Hershbein (2012) uses the national unemployment rate as the explanatory variable, whereas I use the state unemployment rate and control for state fixed effects and nationwide year effects.

The comparison between whites and blacks is closely related to the literature on the differential effects of a recession at entry across groups with different skill levels and educational backgrounds. In particular, Kahn (2010); Speer (2015) are most relevant in that both studies use the same dataset and an empirical strategy very similar to this study. Kahn (2010) shows a persistent negative effect of the unemployment rate at graduation on wages for white male college graduates. In contrast, Speer (2015) shows that the initial impact of a recession at graduation on employment and wages is substantial for high school graduates, but these effects diminish quickly. A similar pattern is observed by Genda et al. (2010) using the Current Population Survey (CPS). Blacks are on average less educated than whites are, and racial minorities and lessskilled workers share a similar vulnerability to business cycle conditions. Therefore, theoretically, it is possible that the effect of a recession at entry for blacks and whites is similar to that for high school graduates and college graduates, respectively. However, I do not find as clear a difference between blacks and whites as the existing studies found between college and high school graduates. At the same time, despite the statistical insignificance, the pattern of black-white difference depicted by the point estimates resembles the difference between high school and college graduates to some extent. 
It is important to keep in mind that whether the effect of labor market conditions at entry is weaker for disadvantaged workers depends on the institutional settings. For example, Genda et al. (2010) show that the effect of high unemployment at graduation is more negative and persistent for high school graduates than for college graduates in Japan. Furthermore, Brunner and Kuhn (2014) show a more negative and persistent effect for blue-collar workers than for white-collar workers in Austria. On the other hand, Raaum and Røed (2006) find that the effects of the unemployment rate experienced in youth tend to be more persistent for those with advantaged backgrounds in Norway. Moreover, a recession at entry could increase the incidence of nonemployment in subsequent years without affecting the wage rate for less-educated men in countries with a rigid labor market structure such as Belgium (Cockx and Ghirelli 2015) and Spain (Fernández-Kranz and Rodríguez-Planas 2015). Therefore, my findings may not be generalizable to minorities in countries with rigid labor market structures. However, these findings provide useful insights for countries with flexible labor market structures similar to those in the United States.

Lastly, this study relates to the broader literature of differential effects of labor market conditions across different demographic groups. Although it is controversial whether an economic upturn benefits economically disadvantaged people as much as the more advantaged, ${ }^{5}$ there is little doubt that the costs of a downturn are borne disproportionately by the disadvantaged (Clark and Summers 1981; Cutler and Katz 1991; Hines et al. 2001; Hoynes et al. 2012). Studies on cyclical upgrading of the labor force (Devereux 2004; Okun 1973) also suggest that less-skilled workers tend to lose their jobs in recessions, while more-skilled workers tend to move upward to higher-paying jobs in booms. Since the contemporaneous labor market conditions affect blacks significantly (Altonji and Blank 1999), the initial impact of a recession at entry is expected to be stronger for them. On the other hand, however, the vulnerability to aggregate shocks after entry to the labor market may reduce the persistence of a negative shock at entry.

\section{Predictions from economic theories}

Several confounding factors can produce persistent negative effects of a recession at entry to the labor market on subsequent employment and wages. First, search frictions prolong the process to resolve the initial worker-job mismatch. That is, it takes time and money to find a good job under incomplete information about available job opportunities. Oreopoulos et al. (2012) find that the job turnover rate remains high for 8-10 years for cohorts that graduated from college during a recession, suggesting that the matching process takes longer for them.

Furthermore, the nominal wage rigidity may prevent firms from reducing incumbent workers' wages even during a recession. Thus, an individual lucky enough to have entered the labor market during a boom may be able to maintain a relatively high-paying job. Indeed, Beaudry and DiNardo (1991) find that incumbent workers' wages do not fall during recessions as long as the workers remain employed, and they explain this by implicit long-term wage contracts with mobile workers.

These advantages of obtaining a high-wage job at entry disappear when the worker leaves the job without moving to a better position. Thus, the effect of obtaining a highwage job at entry is less persistent for workers who tend to quit because of exogenous 
reasons. Since women are more likely to quit jobs for childcare and other household needs, the effect of recessions at entry is expected to be less persistent for women than for men.

The initial impact of a recession is stronger for groups more sensitive to temporary fluctuations of labor demand in the entry-level labor market. Since unemployment rates for blacks are more sensitive to business cycle conditions (Altonji and Blank 1999; Hoynes et al. 2012), ${ }^{6}$ the initial impact is expected to be stronger for blacks. However, it is unclear whether this negative shock at entry persists for them, because they are more vulnerable to fluctuations in labor demand later in their career, and thus, blacks who entered labor market during a boom may not able to maintain a good job obtained at entry.

In addition, missing opportunities for on-the-job training due to a poor match can aggravate the negative effect of entering the labor market during a recession. Although it is ambiguous whether the loss of training opportunities matters more to blacks than to whites, women's weaker labor force attachment implies less incentive for firms to invest in human capital for them. Thus, this result predicts a weaker effect of a recession at entry on subsequent wages for women than for men.

\section{Data: NLSY79}

My primary data source is the National Longitudinal Survey of Youth 1979 (NLSY79), which consists of a representative sample of the noninstitutionalized U.S. civilian segment of population aged 14-22 in 1979, interviewed annually from 1979 to 1994 and biennially from 1996 to the present. For this study, I use data from 1979 to 2000 and limit my sample to the cross-sectional sample of whites and blacks and the supplemental samples of blacks. ${ }^{7}$ I drop observations that have missing information necessary to define the year and the state of entry; the detailed sample restrictions are described in the appendix. Finally, 5387 individuals remain in the sample.

\subsection{Definition of the year and state of entry}

The year of labor market entry is defined as the last year of enrollment. The cases of enrollment for up to two years in colleges after not being enrolled at least for a year and enrollment after the age of 30 are not considered. ${ }^{8}$ The survey variables used to define the last year of enrollment is the enrollment status of respondents as of May 1 in each year, and the last month and year in school asked in 1979 for those who were not enrolled in 1979. Note that I do not use the highest grade completed here, and the year of entry is defined not only for those who graduated from a school but also for those who did not complete the degree or grade after enrollment. For example, if an individual was in $12^{\text {th }}$ grade in 1980 and was not enrolled for years after 1980, the year of entry for the individual is 1980, regardless of his/her age at that time or whether this individual completed the high school diploma.

The state of entry is defined as the state of residence in the year of entry for those whose entry year is 1979 or later. For those who entered before 1979, I use the state of residence in 1979 because data pertaining to the state of residence prior to 1979 is not available. This definition is the same as that in Maclean $(2014,2015)$.

Table 1 summarizes the number of individuals of each race-gender group and average state unemployment rates by the year of labor market entry. Approximately $90 \%$ of the 
Table 1 Number of individuals and mean unemployment rate by year of entry

\begin{tabular}{|c|c|c|c|c|c|c|}
\hline Year of entry & U. rates & White men & White women & Black men & Black women & Total \\
\hline 1973 & 4.88 & 3 & 5 & 3 & 1 & 12 \\
\hline 1974 & 5.97 & 12 & 16 & 9 & 10 & 47 \\
\hline 1975 & 10.90 & 57 & 79 & 35 & 41 & 212 \\
\hline 1976 & 7.39 & 86 & 116 & 46 & 48 & 296 \\
\hline 1977 & 6.84 & 103 & 138 & 62 & 62 & 365 \\
\hline 1978 & 6.03 & 116 & 133 & 76 & 101 & 426 \\
\hline 1979 & 5.81 & 155 & 202 & 94 & 117 & 568 \\
\hline 1980 & 7.41 & 151 & 183 & 103 & 121 & 558 \\
\hline 1981 & 7.89 & 174 & 185 & 87 & 125 & 571 \\
\hline 1982 & 10.26 & 155 & 182 & 94 & 132 & 563 \\
\hline 1983 & 10.12 & 124 & 126 & 61 & 83 & 394 \\
\hline 1984 & 7.61 & 97 & 110 & 56 & 66 & 329 \\
\hline 1985 & 7.34 & 92 & 95 & 34 & 49 & 270 \\
\hline 1986 & 7.15 & 81 & 98 & 28 & 34 & 241 \\
\hline 1987 & 6.43 & 55 & 65 & 16 & 34 & 170 \\
\hline 1988 & 5.67 & 34 & 41 & 9 & 17 & 101 \\
\hline 1989 & 5.27 & 31 & 25 & 9 & 15 & 80 \\
\hline 1990 & 5.96 & 16 & 23 & 8 & 14 & 61 \\
\hline 1991 & 6.83 & 15 & 17 & 3 & 9 & 44 \\
\hline 1992 & 7.61 & 9 & 8 & 4 & 6 & 27 \\
\hline 1993 & 6.66 & 3 & 7 & 3 & 0 & 13 \\
\hline Total & 7.64 & 1569 & 1854 & 840 & 1085 & 5348 \\
\hline
\end{tabular}

sample entered the labor market during the 12 years between 1975 and 1986, the period including the recessions in 1975 and 1982-83.

\subsection{Outcome variables}

The main outcome variable is the log real hourly wages. The real wages are deflated by the consumer price index normalized to the price level in 1982-1984. The hourly wages in the NLSY are defined as "hourly rates of pay at the current or most recent job." I dropped observations with nominal hourly wages exceeding 1000 dollars. This variable is available for anyone who reported that he or she was employed since the last interview. Thus, jobs include not only full-time jobs, but also part-time ones.

I allow for college enrollment up to 2 years after entry to the labor market, and if the respondents worked while in college, I include them in the wage data. I find that $2.86 \%$ of the observations with valid wages and within 12 years since entry are enrolled in college. Furthermore, a recession at entry to the labor market may induce some workers to return to college, thus leading to part-time employment. If so, the estimated effect on wages may include such an effect through college enrollment after entry. Card and Lemieux (2000) show that the positive effect of unemployment rate at age 17 on obtaining college education is stronger for women than for men, implying that women may be more likely to be enrolled later in response to initial labor market conditions. 
If the respondents did not work at all since the last interview, their hourly wages are missing. At the same time, about 3\% respondents are currently employed but lack wages for some unknown reason. Table 2 shows the number of observations with valid (positive) hourly wages, missing wages due to non-employment, and missing wages for other reasons for each race-gender-potential experience cell.

The proportion with missing wages due to non-employment varies across gender and race: women and blacks are less likely to have valid wages. Moreover, labor supply patterns of white women over potential experience are opposite to that of black women. Since the unemployment rate at entry is expected to have a negative effect on subsequent wages, there might be a negative effect on subsequent employment as well. If the likelihood of having a valid wage were affected by the unemployment rate at entry, it would cause a sample selection bias. Thus, I also examine the effects on employment and the likelihood of having a valid wage. As shown later, the unemployment rate at entry does not have a statistically significant negative effect on the likelihood of having a valid wage.

Since data on hourly wages prior to 1978 are not available, the estimates for the short-run impact are based only on cohorts who left school in 1978 or later. This implies that the current data do not allow measurement of the short-term impact of labor market entry around the recession of 1975. Furthermore, those who left school before 1978 tend to be less educated. Thus, the sample with 1-3 years of potential experience underrepresent less-educated individuals.

\subsection{Explanatory variables}

The main explanatory variable is the state unemployment rate at entry. The state unemployment rates based on the CPS are available only from 1976. However, dropping individuals who entered the labor market before 1975 may unbalance the composition of birth-year cohorts by making older cohorts more educated on average. Thus, I use the state unemployment rates based on the Unemployment Insurance (UI) records for 1973-1975. Since the UI series tends to be lower than the CPS series, I rescale it,

Table 2 Number of observations with and without valid wages (\% of total number of observations in the corresponding race-sex-potential experience category)

\begin{tabular}{llllll}
\hline & Exp. & White men & Black men & White women & Black women \\
\hline With valid wages & $1-3$ & $3715(88.7 \%)$ & $1666(75.4 \%)$ & $3962(81.6 \%)$ & $1853(63.3 \%)$ \\
& $4-6$ & $4248(93.2 \%)$ & $2101(85.4 \%)$ & $4418(81.8 \%)$ & $2220(70.0 \%)$ \\
& $7-9$ & $4110(94.7 \%)$ & $2066(86.2 \%)$ & $4147(80.6 \%)$ & $2288(74.8 \%)$ \\
& $10-12$ & $3603(94.5 \%)$ & $1824(84.8 \%)$ & $3588(78.0 \%)$ & $2054(74.7 \%)$ \\
Missing wages due to non-employment & $1-3$ & $330(7.9 \%)$ & $466(21.1 \%)$ & $744(15.3 \%)$ & $1002(34.2 \%)$ \\
& $4-6$ & $171(3.8 \%)$ & $293(11.9 \%)$ & $820(15.2 \%)$ & $885(27.9 \%)$ \\
& $7-9$ & $97(2.2 \%)$ & $258(10.8 \%)$ & $854(16.6 \%)$ & $716(23.4 \%)$ \\
& $10-12$ & $81(2.1 \%)$ & $255(11.9 \%)$ & $872(19.0 \%)$ & $629(22.9 \%)$ \\
Missing wages though being employed & $1-3$ & $145(3.5 \%)$ & $78(3.5 \%)$ & $151(3.1 \%)$ & $71(2.4 \%)$ \\
& $4-6$ & $140(3.1 \%)$ & $65(2.6 \%)$ & $161(3.0 \%)$ & $65(2.1 \%)$ \\
& $7-9$ & $131(3.0 \%)$ & $74(3.1 \%)$ & $145(2.8 \%)$ & $55(1.8 \%)$ \\
& $10-12$ & $130(3.4 \%)$ & $72(3.3 \%)$ & $140(3.0 \%)$ & $68(2.5 \%)$ \\
\hline
\end{tabular}


multiplying by the coefficient of the CPS series in a regression of the UI series between 1976 and 1982 on the CPS series of the same year and constant. Details are described in the appendix. Both the CPS- and the UI-based unemployment rates are annual averages.

I also control for the state unemployment rate of the current residence, the years of schooling, and the age-adjusted Armed Forces Qualification Test (AFQT) score. The variable for the years of schooling is "highest grade completed as of May 1." The AFQT score is the percentile score of the test, which was attached to the NLSY in 1981 and is often used as a measure of ability in studies using the NLSY79. I adjust the score to the age at which the respondent took the test by taking a z-score of the raw percentile score within each birth-year cohort. ${ }^{9}$

\section{Descriptive statistics}

Figure 1 plots the average log real hourly wages over potential experience (years since entry) for the four demographic groups: white men, black men, white women, and black women. To see how the observed average wage profiles vary with labor market conditions at entry, I split each demographic group into two subgroups: one with unemployment rate at entry higher than the median and the other with that lower than the median. First, the upper left panel shows a gradually fading wage gap for white men. This pattern is consistent with the results by Kahn (2010); Oreopoulos et al. (2012). For black men, the lower left panel shows a substantial wage gap in the first few years, which disappears by the fifth year.

Regarding women, the upper right panel shows a very small gap among white women. The smaller gaps for women than men are consistent with the theories that predict a weak effect on those with weak labor force attachment. Surprisingly, black

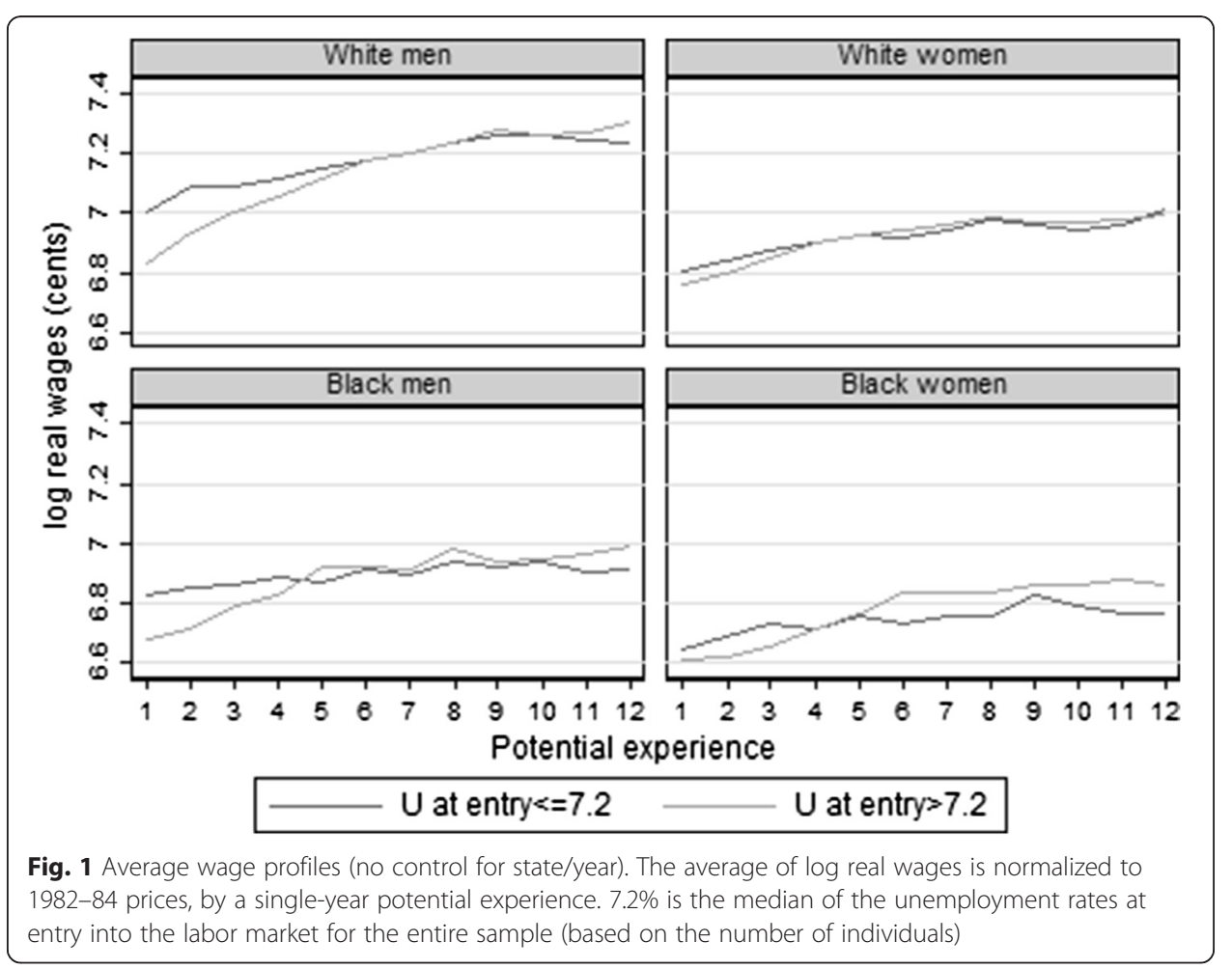


women who left school during recessions earn more in their fifth year and later. However, this may be spurious due to accidental positive selection on educational background, as shown in Table 3, or a state-specific component that happened to correlate with the unemployment rates.

Table 3 shows summary statistics of educational background and the age-adjusted AFQT scores by gender, race, and unemployment rate at entry. The highest grades completed are almost equal among those who entered the labor market during recessions and booms, except that black women who entered during recessions are slightly more educated than those who entered during booms. The age-adjusted AFQT score is also slightly higher for black women with higher unemployment rates at entry. Except for this, there is little difference between the groups with higher and lower unemployment across gender and race. At least, people who left school during recessions are not negatively selected on the basis of education or pre-market human capital measured by the AFQT.

The bottom row of Table 3 shows that the numbers of white men and women in the groups with unemployment rate at entry higher and lower than the median are approximately equal and that black men and women are more likely to have graduated when the unemployment rate was low. This difference mainly comes from the difference in race compositions across states, suggesting that it is essential to control for the entry-state fixed effects. Furthermore, the timing and location of entry may be endogenous because people may try to avoid entering the labor market during recessions. The next section describes the strategies to deal with these issues.

\section{Empirical strategy}

\subsection{Baseline model}

My primary objective in this study is to identify the effect of the unemployment rate at labor market entry on subsequent wages for each gender and race group. To observe the differences in persistence, I also allow the effect of the unemployment rate at entry to vary with potential experience (years since leaving school).

Since the state unemployment rate may correlate with unobserved characteristics of each state, which in turn may affect young workers' wages, it is essential to control for the entry-state fixed effects. This is especially crucial for the comparison of blacks and

Table 3 Means of explanatory variables by race, gender and unemployment rate at entry

\begin{tabular}{llllll}
\hline & & White men & Black men & White women & Black women \\
\hline Highest grades completed & $\mathrm{U}<=7.2 \%$ & 13.4 & 12.4 & 13.4 & 12.7 \\
& $\mathrm{U}>7.2 \%$ & 13.4 & 12.3 & 13.4 & 13.0 \\
& Total & 13.4 & 12.4 & 13.4 & 12.8 \\
Age adjusted AFQT score & $\mathrm{U}<=7.2 \%$ & 0.25 & -0.93 & 0.16 & -0.93 \\
& $\mathrm{U}>7.2 \%$ & 0.27 & -0.95 & 0.19 & -0.82 \\
& Total & 0.26 & -0.94 & 0.17 & -0.88 \\
Number of individuals & $\mathrm{U}<=7.2 \%$ & 778 & 442 & 938 & 593 \\
& $\mathrm{U}>7.2 \%$ & 791 & 398 & 916 & 492 \\
& Total & 1569 & 840 & 1854 & 1085 \\
\hline
\end{tabular}

Note: $7.2 \%$ is the median of the unemployment rates at entry among all individuals in the sample 
whites given the considerably different racial composition across states. In addition, since less-educated people entered the labor market earlier than the others within the same birth-year cohort, temporary macro shocks in the year of entry can correlate with the years of schooling and cause bias. In particular, it is important to keep in mind that the majority of the sample who graduated from school during the recession in 19821983 are college graduates.

To control for state fixed effects and entry year effects, I include dummy variables for the state and year of entry, respectively. The identification of the effect of high unemployment at entry relies on the variations in unemployment rates at the year- and state- level net of those fixed components. Given the strong auto-correlation of unemployment rates, I also need to control for the current unemployment rate so that the estimated coefficients are not affected by business cycle fluctuations.

If the sample size was large enough, I could allow state fixed effects to vary with both gender and race. However, some states have too few blacks to include entry-state dummies if I limit the sample to blacks. Therefore, I employ a parsimonious specification that pools blacks and whites together, while I run separate regressions for men and women. To incorporate the difference in racial wage gaps across regions, I include dummy variables for the 10 BEA regions of residence in the school-leaving year interacted with a dummy variable for blacks.

Specifically, I consider the following wage function:

$$
\log w_{i t \tilde{s} y s g}=\alpha_{(t-y) \cdot g}+\beta_{(t-y) \cdot g} u_{y s}+\gamma_{(t-y) \cdot g} u_{t \tilde{s}}+\delta^{\prime} X_{i t}+\phi_{t}+\eta_{s}+\theta_{r g}+\mu_{y}+\varepsilon_{i t y s g}
$$

where $w_{i t s \tilde{y} s g}$ is the real hourly wage of individual $i$ belonging to demographic group g, who left school in year $y$ and in state $s$ observed in calendar year $t$ and state $\tilde{s} . \alpha_{(t-y), g}$ is a coefficient of potential experience dummy, $u_{y s}$ is the unemployment rate of the year and the state of entry into the labor market, $u_{t \tilde{s}}$ is the current unemployment rate in the state of current residence, and $X_{i t}$ represents other control variables including potential experience, the highest grade completed, and the age-adjusted AFQT score.

To take into account the differences in the wage-experience profiles and sensitivity to aggregate labor market conditions across race groups, I allow the intercept, $\alpha_{(t-y), g}$, and the coefficients of unemployment rates, $\beta_{(t-y), g}$ and $\gamma_{(t-y), g}$, to vary across race and with potential experience. Note that each coefficient represents the effect for each demographic group, not the difference from a reference group (there is no "reference group"). Equation (1) is estimated separately for men and women.

Unobserved error components are decomposed into a calendar year fixed effect $\phi_{t}$, an entry-state fixed effect $\eta_{s}$, a region-specific black-white gap $\theta_{r g}$, an entry-year fixed effect $\mu_{y}$, and the remaining error $\varepsilon_{i t y s}$. Since the time-variant error term, $\varepsilon_{i t y s}$, can be correlated within states across years, the standard errors are clustered at the state level. Sampling weights are not used for any regressions. ${ }^{10}$

\subsection{Endogenous determination of timing and location of entry}

Even after controlling for state-fixed effects and nation-wide entry year effects, a potential source of bias remains if the timing and location of labor market entry are endogenous and affected by business cycle conditions. In particular, people may determine their timing and location of entry accordingly to avoid entry during 
recessions. Existing studies show that a high unemployment rate may increase enrollment to schools for two reasons: the relatively low opportunity cost of not working and avoidance of entering the slack labor market. Concerned mainly with the first aspect, Card and Lemieux (2000) have shown that a temporary rise of the local unemployment rate increases high school enrollment for ages 15-17, using the CPS. In contrast, the effect on college enrollment is weak, indecisive for men and slightly negative for women. A similar concern applies to the geographical mobility. Using the Census data, Wozniak (2010) reports that college graduates tend to move to states with high labor demand when they enter the labor market, although less-educated people do not move as often.

To address the endogeneity issue regarding the timing and location of college graduation, Kahn (2010) uses the unemployment rate in the year when an individual turned 22 and the state of residence at age 14. Following this approach, I use the unemployment rate in the year of predicted entry and state of residence at age 14 as an instrument for the state unemployment rate in the actual year and state of entry. Specifically, I define the year of predicted entry based on the highest degree/diploma attained as follows: year of birth +18 for those without any degree/diploma and those with highschool diploma or equivalent, year of birth +20 for those with associate degrees and year of birth +22 for those with bachelor or graduate degrees. ${ }^{11}$ Although the highest degree/diploma attained is a choice variable, from a practical viewpoint, it would be difficult to define entry using a single age for everyone. The unemployment rates at age 18 and younger do not have predictive power strong enough to work as an instrument for college graduates. The unemployment rates at older ages are unlikely to be independent of the error term, since the business cycle conditions in the first few years after entry may affect subsequent wages for high school graduates. Maclean (2014, 2015) uses the same data and similar instrumental variables.

The key assumption here is that the highest degree/diploma attained and the state of residence at age 14 are independent from the state unemployment rate in the year of predicted entry. While the state of residence at age 14 is plausibly exogenous, theoretically, it is not clear whether the highest diploma/degree attained is affected by business cycle conditions. In theory, the decision to attain a degree is a choice and those who proceed to college during a recession might be different from those who proceed to college during a boom. Empirically, however, Kahn (2010) shows that the correlations between characteristics of college graduates and the unemployment rate at age 18 are weak for white men in the NLSY79, suggesting that such endogeneity may be practically negligible. Using the CPS, Genda et al. (2010) also show that the future earnings of college graduates, which they use as a proxy for potential productivity, are not correlated with the unemployment rate at age 18. Furthermore, Card and Lemieux (2000) find that the effect of the local unemployment rate at around high school graduation on college enrollment is weak, although they find a statistically significant effect on high school enrollment.

Note that what matters here is the enrollment behavior of young people who have just graduated from high school. It is true that the enrollment of community college is countercyclical (Betts and McFarland 1995), and the 2-year college enrollment of people who have some labor market experience is quite sensitive to labor market conditions and policies (Barr and Turner 2015). Since I define the year of entry as the last 
year of enrollment, excluding college enrollment for less than two years after more than a year out of school, this cyclical enrollment of community college does not affect the year of entry used in this study.

Hence, I use age 18, 20, or 22 as the age of predicted entry, depending on the highest degree attained. Later in this section, I confirm that a high unemployment rate does not induce people to earn an additional undergraduate degree in college, although it seems to induce some people to continue in college. Note that the information on college degree is not based on the years of schooling, but is directly obtained from the respondents. ${ }^{12}$ Thus, it is not affected by respondents' continuity in college without obtaining additional degrees. I assign the year of birth +18 to high school drop-outs because Card and Lemieux (2000) find positive effects of the unemployment rate on high school completion. Likewise, I ignore graduate degrees because Kahn (2010) reports that a recession at graduation from college slightly increases the likelihood of attaining a graduate degree.

To know if the unemployment rate at actual or predicted entry or that at age 18 affects the year and state of entry, I estimate several regressions on the entire sample (not multiple observations per person) in the following form:

$$
\text { Dept. } \operatorname{var}_{i}=\beta_{g} u_{i}+\delta^{\prime} X_{i}+F E s+\varepsilon_{i}
$$

The results are summarized in Table 4. The first column of Table 4 indicates the dependent variables, and the second column indicates what $u_{i}$ stands for: the unemployment rate at actual entry, at age 18 , or at predicted entry. $X_{i}$ includes the race dummy and the age-adjusted AFQT score, and FEs represent a set of fixed effects appropriate for the corresponding $u_{\mathrm{i}}$ (see the notes below Table 4). The dependent variables in rows (2)-(4) are discrete choice indices, and the estimates reported in Table 4 are from the linear probability model for the sake of intuitive grasp. ${ }^{13}$

Row (1) suggests weak positive effects of the unemployment rates on years of schooling, which is consistent with the findings by Card and Lemieux (2000), although the effect of the unemployment rates at age 18 is not statistically significant probably due to the large standard errors. However, the effect on the likelihood of having a college degree (row (2)) is not statistically significant either and seems to be economically small as well: a 1 percentage-point rise in the unemployment rate changes the likelihood of

Table 4 Correlation with unemployment rates at entry or age 18 and options upon graduation

\begin{tabular}{llllll}
\hline Dependent var. & $U$ at & White men & Black men & White women & Black women \\
\hline (1) Years of schooling & Actual entry & $0.024[0.027]$ & $-0.009[0.033]$ & $0.059[0.026]^{* *}$ & $0.062[0.030]^{* *}$ \\
& Age 18 & $0.047[0.045]$ & $0.027[0.047]$ & $-0.006[0.039]$ & $0.008[0.040]$ \\
$\begin{array}{l}\text { (2) Having a college degree } \\
\text { (AA, BA, BS) }\end{array}$ & Age 18 & $0.013[0.009]$ & $0.007[0.009]$ & $-0.003[0.009]$ & $-0.006[0.009]$ \\
$\begin{array}{l}\text { (3) Actual entry is later than } \\
\text { predicted entry }\end{array}$ & Predicted entry & $0.011[0.014]$ & $0.009[0.014]$ & $0.013[0.014]$ & $0.021[0.015]$ \\
$\begin{array}{l}\text { (4) Having changed state of } \\
\text { residence }\end{array}$ & Actual entry & $-0.003[0.006]$ & $0.004[0.007]$ & $-0.004[0.005]$ & $-0.002[0.006]$
\end{tabular}

Note: OLS regressions (the linear probability model for rows (2)-(4)). The regressions on the unemployment rate at actual entry include dummies for year of entry and state of residence at entry. The regressions on the unemployment rate at age 18 include dummies for year of birth and state of residence at age 14. The regression on the unemployment rate at predicted entry includes dummies for year of predicted entry and state of residence at age 14. Standard errors are in brackets, clustered by the relevant pair of the year and the state. ${ }^{* *}$ indicates statistically significant at the $5 \%$ level 
proceeding to college at most by 1 percentage-point. ${ }^{14}$ Even if some people avoid entering the labor market by continuing in school, this does not affect the final degree attainment, perhaps because they can postpone or hasten completion of the degree without changing the targeted degree itself. Rows (3) and (4) show no strong evidence that people avoid graduating during a recession.

Overall, the unemployment rates at actual entry is correlated with the years of schooling, but the correlation between labor market conditions at age 18 and options upon graduation is very weak for this sample. Therefore, I correct for this potential endogeneity of entry by instrumenting for $u_{y s}$ with the unemployment rate in the predicted year of graduation based on the highest degree attained and the state of residence at age $14 .^{15}$

Since the unemployment rate at entry is interacted with the four race-gender groups and the four 3-year potential experience brackets, there are 16 pairs of endogenous variables and corresponding instruments. Therefore, there are 16 separate first-stage regressions. For easier grasp of the correlation between the unemployment rates at actual entry and at predicted entry, I also estimate the following collapsed regression:

$$
u_{y s}=\beta_{g} u_{\tilde{y} \tilde{s}}+\delta^{\prime} X_{i}+\eta_{\tilde{s}}+\theta_{r g}+\mu_{\tilde{y}}+\varepsilon_{i}
$$

where $\tilde{y}$ is the year of predicted entry and $\tilde{s}$ is the state of residence at age 14. Equation (3) is estimated separately for men and women. $\beta_{g}$ varies across race. $X_{i}$ includes the race dummy, the age-adjusted AFQT score, and years of schooling. $\eta \tilde{s} \theta_{r g} \mu_{\tilde{y}}$ are the fixed effects corresponding to the subscripts. The dataset consists of persons, not multiple observations per person.

The upper panel of Table 5 reports estimated $\beta_{g}$ : they are in the range of $0.37-0.51$, and the value of $\mathrm{t}$-statistics is approximately 10 . The correlation between the endogenous variable and the instrument is strong enough for all four race-gender groups. The lower panel of Table 5 reports the coefficient of the instrument in the actual first stage regressions common to the IV estimates reported in Tables 6, 7 and 8. It shows only the coefficient of the instrument corresponding to the endogenous variable in each regression. For example, the upper right cell implies that a unit increase of the instrument is associated with an increase of the unemployment rate at actual entry by 0.454 for white men with 1-3 years of potential experience. The differences over potential experience are probably due to change in the composition of the sample caused by entry before 1979, which affect the group with 1-3 years of experience the most.

Table 5 Coefficients of instruments in the first stage regressions

\begin{tabular}{|c|c|c|c|c|}
\hline & White men & Black men & White women & Black women \\
\hline Collapsed regressions & $0.503[0.042]^{* * *}$ & $0.455[0.054]^{* * *}$ & $0.508[0.043]^{* * *}$ & $0.378[0.047]^{* * *}$ \\
\hline \multicolumn{5}{|c|}{ Actual first stage (16 separate regressions) } \\
\hline Potential Exp $=1-3$ & $0.454[0.006]^{* * *}$ & $0.441[0.006]^{* * *}$ & $0.455[0.006]^{* * *}$ & $0.316[0.006]^{* * *}$ \\
\hline Potential Exp $=4-6$ & $0.574[0.007]^{* * *}$ & $0.523[0.007]^{* * *}$ & $0.589[0.006]^{* * *}$ & $0.404[0.006]^{* * *}$ \\
\hline Potential Exp $=7-9$ & $0.562[0.007]^{* * *}$ & $0.508[0.007]^{* * *}$ & $0.588[0.006]^{* * *}$ & $0.428[0.006]^{* * *}$ \\
\hline Potential Exp $=10-12$ & $0.557[0.006]^{* * *}$ & $0.534[0.006]^{* * *}$ & $0.589[0.006]^{* * *}$ & $0.454[0.006]^{* * *}$ \\
\hline
\end{tabular}

Note: Each coefficient is taken from a different regression, see the text for detail. Standard errors are in brackets, clustered by the year of predicted entry and the state of residence at age $14 .{ }^{* * *}$ indicates statistically significant at the $1 \%$ level 
Table 6 The effect of the unemployment rate at entry on wages

\begin{tabular}{|c|c|c|c|c|}
\hline & \multicolumn{2}{|l|}{ OLS } & \multicolumn{2}{|l|}{ IV } \\
\hline & Men & Women & Men & Women \\
\hline \multicolumn{5}{|l|}{$U$ at entry } \\
\hline White $\exp =1-3$ & $-0.016[0.006]^{* *}$ & $-0.008[0.006]$ & $-0.030[0.016]^{*}$ & $0.006[0.015]$ \\
\hline White $\exp =4-6$ & $-0.011[0.006]^{*}$ & $-0.006[0.006]$ & $-0.027[0.011]^{* *}$ & $-0.002[0.011]$ \\
\hline White $\exp =7-9$ & $-0.008[0.006]$ & $-0.003[0.006]$ & $-0.019[0.012]$ & $-0.002[0.011]$ \\
\hline White exp $=10-12$ & $-0.007[0.006]$ & $-0.005[0.007]$ & $-0.029[0.012]^{* *}$ & $-0.004[0.014]$ \\
\hline Black exp $=1-3$ & $-0.019[0.008]^{* *}$ & $-0.025[0.007]^{* * *}$ & $-0.051[0.023]^{* *}$ & $-0.034[0.028]$ \\
\hline Black exp $=4-6$ & $-0.013[0.009]$ & $-0.014[0.007]^{* *}$ & $-0.049[0.019]^{* *}$ & $-0.015[0.019]$ \\
\hline Black exp = 7-9 & $0.000[0.009]$ & $-0.007[0.007]$ & $-0.034[0.020]^{*}$ & $0.003[0.018]$ \\
\hline Black exp $=10-12$ & $0.008[0.009]$ & $-0.001[0.007]$ & $-0.028[0.023]$ & $0.024[0.018]$ \\
\hline Highest grade completed & $0.062[0.005]^{* * *}$ & $0.080[0.004]^{* * *}$ & $0.057[0.005]^{* * *}$ & $0.077[0.005]^{* * *}$ \\
\hline Age adjusted AFQT score & $0.104[0.010]^{* * *}$ & $0.105[0.010]^{* * *}$ & $0.108[0.010]^{* * *}$ & $0.108[0.011]^{* * *}$ \\
\hline Observations & 22,947 & 24,233 & 22,333 & 23,404 \\
\hline R-squared & 0.30 & 0.30 & 0.30 & 0.29 \\
\hline
\end{tabular}

Note: The dependent variable is log real hourly wages (cents). Constant, current unemployment rates interacted with race and the 3-year experience brackets, a race dummy, non-linear controls for potential experience differentiated by race are also included in the regressions though omitted from the table. OLS regressions include dummies for year of entry, state of residence at entry and year of the survey; IV regressions include dummies for year of predicted entry, state of residence at age 14 and year of the survey. Standard errors are in brackets, clustered by the year and the state of entry (predicted entry for IV). ${ }^{* * *}, *^{* *},{ }^{*}$ indicate statistically significant at the $1 \%, 5 \%$ and $10 \%$ level, respectively

\section{Results}

The first two columns of Table 6 reports the OLS estimates of $\beta_{(t-y), g}$ in equation (1), the coefficients of the unemployment rate at entry interacted with race and potential experience, estimated by separate OLS regressions for men and women. Not surprisingly, there are negative effects immediately after entry for all demographic groups except for white women. However, the size and persistence of the effects differ across

Table $\mathbf{7}$ The effect of the unemployment rate at entry on employment

\begin{tabular}{|c|c|c|c|c|}
\hline & \multicolumn{2}{|l|}{ OLS } & \multicolumn{2}{|l|}{ IV } \\
\hline & Men & Women & Men & Women \\
\hline \multicolumn{5}{|l|}{$U$ at entry } \\
\hline White $\exp =1-3$ & $0.000[0.005]$ & $0.009[0.004]^{*}$ & $-0.002[0.011]$ & $0.003[0.012]$ \\
\hline White exp $=4-6$ & $0.000[0.004]$ & $0.002[0.004]$ & $0.002[0.007]$ & $0.004[0.009]$ \\
\hline White exp $=7-9$ & $0.003[0.004]$ & $0.005[0.005]$ & $0.006[0.007]$ & $0.007[0.009]$ \\
\hline White $\exp =10-12$ & $0.004[0.004]$ & $0.005[0.005]$ & $0.001[0.008]$ & $0.008[0.010]$ \\
\hline Black exp $=1-3$ & $0.002[0.007]$ & $0.001[0.007]$ & $-0.003[0.017]$ & $0.033[0.022]$ \\
\hline Black exp $=4-6$ & $0.005[0.006]$ & $-0.001[0.007]$ & $0.005[0.013]$ & $0.010[0.015]$ \\
\hline Black exp $=7-9$ & $0.010[0.006]$ & $0.005[0.006]$ & $0.003[0.014]$ & $-0.003[0.016]$ \\
\hline Black exp $=10-12$ & $0.012[0.006]^{*}$ & $0.011[0.007]$ & $-0.008[0.015]$ & $-0.011[0.016]$ \\
\hline Highest grade completed & $0.023[0.002]^{* * *}$ & $0.045[0.003]^{* * *}$ & $0.023[0.003]^{* * *}$ & $0.047[0.003]^{* * *}$ \\
\hline Age adjusted AFQT score & $0.035[0.006]^{* * *}$ & $0.043[0.008]^{* * *}$ & $0.037[0.006]^{* * *}$ & $0.051[0.008]^{* * *}$ \\
\hline Observations & 25,688 & 31,460 & 24,992 & 30,430 \\
\hline R-squared & 0.13 & 0.13 & 0.13 & 0.13 \\
\hline
\end{tabular}

Notes: The dependent variable takes one if the respondent is employed. Linear probability model with the same right hand side variables as the OLS regressions in Table 6; see notes for Table $6{ }^{* * *}$ and ${ }^{*}$ indicate statistically significant at the $1 \%$ and $10 \%$ level, respectively 
Table 8 The effect of the unemployment rate at entry on likelihood of having a valid wage

\begin{tabular}{|c|c|c|c|c|}
\hline & \multicolumn{2}{|l|}{$\underline{\text { OLS }}$} & \multicolumn{2}{|l|}{ IV } \\
\hline & Men & Women & Men & Women \\
\hline \multicolumn{5}{|l|}{$U$ at entry } \\
\hline White $\exp =1-3$ & $0.002[0.004]$ & $0.004[0.004]$ & $0.008[0.009]$ & $-0.002[0.011]$ \\
\hline White $\exp =4-6$ & $0.000[0.003]$ & $0.005[0.004]$ & $0.004[0.006]$ & $0.007[0.008]$ \\
\hline White $\exp =7-9$ & $0.002[0.003]$ & $0.007[0.004]^{*}$ & $0.005[0.006]$ & $0.009[0.008]$ \\
\hline White $\exp =10-12$ & $-0.001[0.003]$ & $0.006[0.005]$ & $0.004[0.006]$ & $0.007[0.009]$ \\
\hline Black exp $=1-3$ & $0.000[0.006]$ & $0.009[0.007]$ & $-0.01[0.016]$ & $0.047[0.021]^{* *}$ \\
\hline Black exp = 4-6 & $0.002[0.005]$ & $0.009[0.007]$ & $0.002[0.011]$ & $0.016[0.014]$ \\
\hline Black exp = 7-9 & $0.008[0.005]$ & $0.008[0.006]$ & $0.000[0.011]$ & $0.008[0.014]$ \\
\hline Black exp = 10-12 & $0.004[0.005]$ & $0.008[0.006]$ & $-0.015[0.012]$ & $-0.015[0.015]$ \\
\hline Highest grade completed & $0.007[0.002]^{* * *}$ & $0.034[0.003]^{* * *}$ & $0.007[0.003]^{* * *}$ & $0.035[0.003]^{* * *}$ \\
\hline Age adjusted AFQT score & $0.026[0.005]^{* * *}$ & $0.035[0.007]^{* * *}$ & $0.026[0.005]^{* * *}$ & $0.041[0.008]^{* * *}$ \\
\hline Observations & 25,688 & 31,460 & 24,992 & 30,430 \\
\hline R-squared & 0.09 & 0.13 & 0.09 & 0.13 \\
\hline
\end{tabular}

Notes: The dependent variable takes one if the observation has a valid (positive) wage. Linear probability model with the same right hand side variables as the OLS regressions in Table 6; see notes for Table $6 * * *$, ** and * indicate statistically significant at the $1 \% .5 \%$ and $10 \%$ level, respectively

demographic groups. For white men, the initial impact is slightly weaker than for black men, but the negative effect remains statistically significant up to 6 years after entry. Furthermore, though statistically nonsignificant, a one percentage point rise in unemployment rate at entry lowers hourly wages by $0.7 \%$ after $10-12$ years. For black men, the effect in fourth to sixth year after entry is not statistically significant, but the size is similar to that for white men. After the first six years, the effect disappears. The effect for white women is not statistically significant even in the first 3 years, and the size of the coefficient is closer to zero. In contrast, the initial impact of a recession at entry for black women is strongest among the four demographic groups, and it remains statistically significant for 6 years. Except that the effect for black women is significantly negative, these observations are essentially the same as what Fig. 1 suggested.

The last two columns of Table 6 report the IV estimates in the same manner as the OLS results. Here, the unemployment rate in the state and the year of actual entry is instrumented by the unemployment rate that the person would have experienced if he/ she had stayed in the same state since he/she was 14 years old and had attained his/her final degree on time. This instrumental variable should correct the biases from endogenous choice of timing and location of graduation conditional on the highest degree attained. The endogeneity of entry seems to bias the OLS estimates toward zero for men. Note that IV estimators in general have larger standard errors than the corresponding OLS estimators; in fact, the standard errors in the last two columns in Table 6 are much larger than those in the first two columns. In particular, the negative effect for black women is not statistically significant, but this is mainly caused by the boosted standard errors.

Table 6 also reports the coefficients of years of schooling and the age-adjusted AFQT score for a comparative analysis. Although not reported in the table, the coefficients of the contemporaneous unemployment rate are not statistically significant, except that 
those for black men are significantly negative. This confirms that black men are the group most affected by the contemporaneous labor market conditions. Each set of fixed effects is jointly statistically significant.

To display the result more intuitively, Fig. 2 plots the coefficients of the unemployment rate at entry from the IV estimates over years since leaving school. Each of the four panels compares men and women of the same race, or blacks and whites of the same gender. Dotted lines show the $95 \%$ confidence intervals.

Panel a compares white men and white women. It confirms that the effect for men is significantly negative, while the effect for women is almost zero. Although the 95\% confidence intervals overlap, the difference between white men and white women looks marginally significant. Furthermore, Appendix $C$ shows that $\beta_{(t-y), g}$ are jointly significant at the $10 \%$ level for white men but not significant for white women. These findings are consistent with the theoretical prediction that the effect of the unemployment rate at entry is weaker and less persistent for those with weaker labor force attachment.

Panel b compares black men and black women. For blacks, the confidence intervals are wider than for whites. Although standard errors are quite large in the first 3 years, the effect for black men tends to be more negative than for black women, like the comparison between white men and women. However, unlike whites, $\beta_{(t-y), g}$ are jointly significant for both black men and women.

Panels c and d compare black and whites of each gender. For both men and women, the confidence intervals for blacks and whites overlap widely. Statistical tests reported in Appendix $C$ also show that $\beta_{(t-y), g}$ are not statically significantly

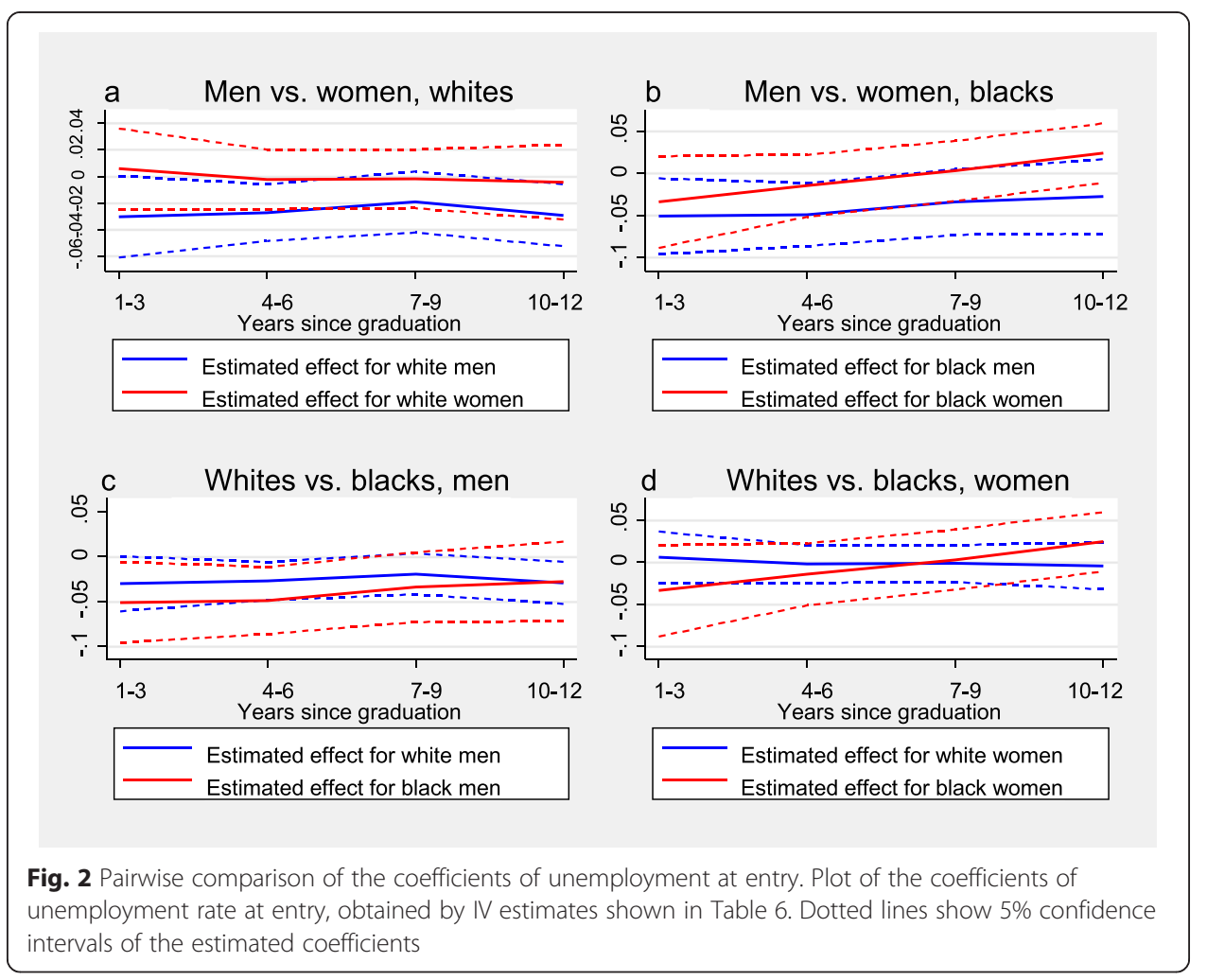


different between blacks and whites, except for the first 3 years after entry for women. However, the differences in point estimates of $\beta_{(t-y), g}$ are not economically negligible. For example, a one percentage point rise in the unemployment at entry can lower hourly wages of black and white men by 5 and 3\%, respectively. Furthermore, the pattern depicted by the point estimates appears to be consistent with the theoretical prediction: the initial impact is stronger for blacks, but they catch up quickly. Therefore, it is hard to conclude whether the effect of a recession at entry differs across race from these results.

If the unemployment rate at entry has a negative effect on wages, it may well have a negative effect on employment. Therefore, I estimate the effect on employment by replacing the dependent variable in equation (1). Table 7 reports the results from the linear probability model. ${ }^{16}$ Surprisingly, the estimated coefficients are mostly positive, although statistically insignificant. If those who were not employed were negatively selected based on their potential wages, this positive effect would cause an upward bias on the estimated effect. Assuming that those with low potential wages are less likely to be employed when there is a negative shock to wages at the cohort level, my estimates are unlikely to be biased downward. Furthermore, the estimates tend to be larger for women, suggesting that decisions on marriages and fertility may matter. Thus, the direction of potential biases is ambiguous.

In any case, recall that non-employment does not necessarily imply missing wages because respondents who have worked since the last interview report wages even if they are not employed in the week of survey. Thus, to examine this issue more directly, Table 8 reports the effect on the likelihood of having a valid wage. The estimated coefficients are still positive but on average smaller and noisier. Moreover, except for the IV estimates of black women, the estimated effects are economically small compared to the effects of years of schooling and the AFQT score. Further, I replace the missing wage data with imputed wages based on several slightly different versions of wage equations with individual fixed effects, and find little differences in the estimated coefficients in the wage regressions. This leads me to believe that, even if there are biases from non-random selection of those lacking valid wages, they will not alter the qualitative conclusions.

\section{Conclusion}

By examining the effect of unemployment rate in the year and state of school-leaving, I have found that the negative effect of a recession at entry is weaker for women than for men. In particular, white women do not seem to be affected by a recession at entry, at least in terms of hourly wages and employment. In addition, the endogeneity of entry seems to cause underestimation of the effect for men. These findings are consistent with the economic theories reviewed in Section 2: the effect of a recession at entry will be stronger for people with stronger labor force attachment.

However, whether the effect differs across race remains unclear. On the one hand, statistical tests cannot reject that the effects for whites and blacks are the same. On the other hand, the differences in point estimates are economically non-negligible. The difference between blacks and whites are somewhat similar but not as clear as the 
differences between high school graduates and college graduates in previous studies (Kahn 2010; Speer 2015; Genda et al. 2010), although I use the same dataset and similar methodology to Kahn (2010); Speer (2015).

Admittedly, the cohorts covered by the NLSY79 entered the labor market a few decades ago, and the labor market structure may have changed since then. Nonetheless, the differences in the sensitivity to contemporaneous labor market conditions across demographic groups have been fairly stable between the 1982 recession and the Great Recession that began in 2008 (Hoynes et al. 2012). Furthermore, the female labor force participation rate has not increased much in the United States since the 1990s, ${ }^{17}$ implying that women still quit jobs for exogenous reasons more often than men do. Thus, I expect that similar patterns across gender and race will be observed for cohorts who graduated around the Great Recession. Whether this expectation is supported empirically needs to be assessed in the future.

It is difficult to distinguish one theory from the others. Note that skill level matters for both access to stable employment in high-paying jobs and returns to training. In theory, once a worker finds a good job after entry, a recession prior to the job change no longer matters in absence of human capital accumulation through the past on-the-job training. Therefore, controlling for labor demand at the beginning of the current job will cancel out the effect of a recession at entry if the loss of training opportunity does not matter. However, it is very difficult to include unemployment rates in the year of leaving school and in the year of beginning of the current job simultaneously, because they are highly collinear. Since this collinearity amplifies the bias caused by misspecification of the effect of tenure and experience, it is necessary to include many interaction terms in the regression. To do so, the required sample size needs to be far larger than the NLSY; this remains for future research.

\section{Endnotes}

${ }^{1}$ Altonji and Blank (1999) show that the unemployment rate for blacks is more sensitive to business cycle conditions. Hoynes et al. (2012) also confirm that the employment rate of blacks is more sensitive to the state unemployment rate.

2 This instrument is used in existing studies using the NLSY79, such as Kahn (2010); Speer (2015); Maclean (2014); Maclean (2015); Maclean et al. (2015).

${ }^{3}$ Relatedly, Gregg (2001) examines the long-term effect on an individual's own experience of unemployment at youth and finds that the effect is weaker for women than that for men, using British data.

${ }^{4}$ Relatedly, Kondo (2012) finds that women who face worse labor market conditions at youth tend to marry earlier, but this is just a temporary shift, and the probability of having married by the age of 30 does not change. Using the NLSY79, the same dataset used in this study, Maclean et al. (2015) also find that a recession at entry has a positive effect on fertility among women.

${ }^{5}$ While Cutler and Katz (1991) argue that the expansion in the mid-late 80s did not benefit the disadvantaged, Hines et al. (2001) view the 1980s as an exception and conclude that the benefits from strong economic growth for the disadvantaged are at least as great as they are for the more advantaged, using data spanning from the 1970s to the 2000s. 
${ }^{6}$ Fig. 4 in Hoynes et al. (2012) shows that a one percentage point increase in the state unemployment rate increases the unemployment rate of white men by one percentage point and that of black men by nearly two percentage point; in this sense, the latter group is twice as sensitive to local labor market conditions than the former one. Moreover, women are less responsive to local labor market conditions, while the racial differences among women are similar to that among men: a 1-percentage point increase in the state unemployment rate increases white women's unemployment rate by about 0.8 percentage point, and black women's unemployment rate by about 1.6 percentage point.

7 I drop the military subsample because it covers only cohorts born between 1957 and 1961. I do not consider the supplemental sample of poor whites because they are excluded from the survey after 1991. I also drop Hispanics because the sample size is too small for a separate analysis.

${ }^{8}$ This definition follows Neumark (2002), who also used the NLSY to identify the effect of early job mobility on adult wages.

9 This process follows Kahn (2010) and other existing studies using the NLSY79.

10 Some existing studies use sampling weights (Maclean 2014, 2015), but others do not (Kahn 2010; Hershbein 2012; Speer 2015). Since the unemployment rate at entry is unlikely to be correlated with the sampling weights, using the sampling weights would not change the results much.

11 The estimated effects from this instrumental variable can be interpreted as the Local Average Treatment Effect (LATE) among people who graduate on time and do not move across states between age 14 and the school-leaving year.

12 Information on the highest degree/diploma attained is not based on the years of schooling completed, but on the following two questions: "What is the highest degree you ever received" and "Do you have a high school diploma or equivalent?"

${ }^{13}$ The results from the probit model are similar in terms of both statistical significance and marginal effects measured at the mean of the explanatory variables.

${ }^{14}$ My estimates are smaller than those in Table 6 in Kahn (2010), which also reported the effect of unemployment rate at age 18 for white men in the NLSY79. This is probably because of differences in sample selection; while Kahn (2010) dropped 1957 cohorts, I dropped those who disappeared from the data by age 30. Card and Lemieux (2000) also report that the effects of the unemployment rate on the likelihood of proceeding to college for students in the $12^{\text {th }}$ grade are statistically insignificant and variable in sign.

15 Note that the information on college degree is not based on the years of schooling, but is directly asked obtained from the respondents; thus, it does not reflect some people staying more than a year without obtaining additional degrees. I assign the year of birth +18 to high school drop-outs because Card and Lemieux (2000) find positive effects of the unemployment rate on high school completion; likewise, I ignore graduate degrees because Kahn (2010) reports that a recession at graduation from college slightly increases the likelihood of attaining a graduate degree.

16 The probit estimates are similar to the corresponding OLS estimates in Tables 7 and 8, with regard to both statistical significance and marginal effects evaluated at the mean of explanatory variables.

${ }^{17}$ The labor force participation rate for women older than 20 years stays around 55$60 \%$ for white women and 60-65\% for black women, according to the Current Population Survey available from the BLS website. 


\section{Appendix A: Sample restrictions and definitions of actual and predicted entry}

On the course of defining the year of entry, I exclude people who dropped out from the survey before turning 30 . In this process, individuals with characteristics associated with higher attrition rate are more likely to be excluded. Therefore, the estimated effect should be interpreted as the effect for those who tend to remain in such longitudinal surveys.

Then, I exclude people with less than 6 years of schooling. The year of entry cannot be defined for people who are still in school at age 30, and those who never went to school since 1979 and miss the year of last enrollment before 1979 . To merge with the state unemployment rate, people have to live in the contiguous United States in the year of entry. I use the state of residence at age 14 as the state of residence at entry for those who entered before 1979. I also exclude people who left school before turning 16 years old and those who have ever served in the army sometime within 12 years since leaving school. Lastly, I exclude people whose state of residence at entry is too small to control state fixed effects (less than 20 people): Delaware, Hawaii, Idaho, Kentucky, Maine, Nebraska, Nevada, New Hampshire, New Mexico, North Dakota, Rhode Island, South Dakota, Utah, Vermont, and Wyoming. The number of people included and excluded is summarized in Table 9.

Table 10 presents a cross-tabulation of age of actual and predicted entry. Many people actually enter the labor market several years after their predicted entry based on the highest degree ever received. This is partly because some people leave college without receiving degrees: approximately $24 \%$ of those with only high school diploma report one or more years in college in response to the question on the highest grade completed. In addition, about $20 \%$ of those assigned 22 as the age of predicted entry have graduate degrees. Others simply did not go straight to their final degree. Even among those who completed the $12^{\text {th }}$ grade, about $10 \%$ have not completed schooling by the age of 20 . For the state, the proportion of people who had moved across states since the age of 14 when they entered the labor market in each race-gender group is $13.6 \%$ for white men, $9.6 \%$ for black men, $14.5 \%$ for white women and $11.6 \%$ for black women.

Table 9 Sample restrictions and sample size (number of individuals)

\begin{tabular}{lll}
\hline & Deleted & Remaining \\
\hline Original NLSY 79 sample & & 12,686 \\
Keep cross sectional white and black and supplemental black samples only; delete & 4847 & 7839 \\
Hispanics, poor white and military sample & & \\
Dropped out from the survey before age 30 & 1837 & 6002 \\
Highest grade completed at age $30<6$ & 6 & 5996 \\
Enrolled at age 30 (except for 2 year college) & 125 & 5871 \\
Not enrolled in 79 and missing last enrollment & 46 & 5825 \\
State of residence at entry is missing & 90 & 5735 \\
Age at entry <16 & 50 & 5685 \\
Served in the army sometime within 12 years since leaving school & 293 & 5392 \\
State of residence at entry was too small (w/ <20 people in sample) & 44 & 5348 \\
\hline
\end{tabular}


Table 10 Age of predicted entry and actual entry

\begin{tabular}{|c|c|c|c|c|c|c|}
\hline \multirow[b]{3}{*}{ Age of actual entry } & \multicolumn{3}{|c|}{ White men } & \multicolumn{3}{|c|}{ White women } \\
\hline & \multicolumn{3}{|c|}{ Age of predicted entry } & \multicolumn{3}{|c|}{ Age of predicted entry } \\
\hline & 18 & 20 & 22 & 18 & 20 & 22 \\
\hline 16 & 54 & 0 & 0 & 68 & 0 & 0 \\
\hline 17 & 61 & 1 & 0 & 99 & 0 & 0 \\
\hline 18 & 368 & 7 & 1 & 474 & 9 & 3 \\
\hline 19 & 244 & 6 & 2 & 211 & 16 & 4 \\
\hline 20 & 82 & 17 & 3 & 97 & 26 & 11 \\
\hline 21 & 45 & 15 & 13 & 36 & 24 & 19 \\
\hline 22 & 31 & 9 & 125 & 33 & 14 & 189 \\
\hline 23 & 29 & 11 & 105 & 27 & 21 & 83 \\
\hline 24 & 18 & 9 & 57 & 25 & 12 & 46 \\
\hline $25-30$ & 63 & 20 & 129 & 88 & 35 & 114 \\
\hline \multirow[t]{3}{*}{ Total } & 995 & 95 & 435 & 1158 & 157 & 469 \\
\hline & \multicolumn{3}{|c|}{ Black men } & \multicolumn{3}{|c|}{ Black women } \\
\hline & \multicolumn{3}{|c|}{ Age of predicted entry } & \multicolumn{3}{|c|}{ Age of predicted entry } \\
\hline Age of actual entry & 18 & 20 & 22 & 18 & 20 & 22 \\
\hline 16 & 28 & 0 & 0 & 31 & 0 & 0 \\
\hline 17 & 67 & 0 & 0 & 58 & 1 & 0 \\
\hline 18 & 172 & 4 & 1 & 241 & 2 & 0 \\
\hline 19 & 188 & 3 & 0 & 176 & 6 & 0 \\
\hline 20 & 96 & 5 & 2 & 88 & 16 & 4 \\
\hline 21 & 39 & 7 & 2 & 80 & 16 & 13 \\
\hline 22 & 28 & 7 & 22 & 46 & 12 & 36 \\
\hline 23 & 13 & 5 & 24 & 29 & 9 & 30 \\
\hline 24 & 15 & 2 & 17 & 21 & 5 & 12 \\
\hline $25-30$ & 33 & 7 & 28 & 64 & 21 & 39 \\
\hline Total & 679 & 40 & 96 & 834 & 88 & 134 \\
\hline
\end{tabular}

The state unemployment rates based on the CPS are available only from 1976. Thus, I used the state unemployment rates based on the Unemployment Insurance (UI) records to obtain state unemployment rates for 1973-1975. Since the UI series tends to be lower than the CPS series, I rescaled it by the following process.

1. For each state, I regress the CPS-based unemployment rate on the UI-based unemployment rate and constant, using data from 1976 to 1982.

2. Using these coefficients, I obtain the predicted value of the CPS-based unemployment rate based on the UI-based unemployment rate for 1973-1975.

Table 11 shows the estimated coefficient and R-squared value for each state, and Fig. 3 illustrates the scatter plots of actual state unemployment rate based on the CPS and the CPS-based rates predicted by the UI-based rates for 1976-1982. In most states, the Rsquared value is fairly high, and the scatter plots show that the error seems to be minimal. 


\section{Appendix B: Unemployment rates for 1973-1975}

Table 11 Coefficients of state-by-state regression of UI- based unemployment rates on BLS state unemployment rates

\begin{tabular}{|c|c|c|c|c|c|c|c|c|c|c|}
\hline & $\mathrm{AL}$ & AK & $\mathrm{AZ}$ & AR & CA & $\mathrm{CO}$ & $\mathrm{CT}$ & $\mathrm{DE}$ & DC & $\mathrm{FL}$ \\
\hline UI based & $2.515^{* *}$ & 0.152 & $1.658^{* * *}$ & $1.310^{* *}$ & $1.593^{* * *}$ & $1.550^{* * *}$ & $1.078^{* * *}$ & $0.751^{* * *}$ & $2.761^{* * *}$ & $1.507^{* * *}$ \\
\hline Unemp. R & {$[0.759]$} & {$[0.234]$} & [0.192] & {$[0.347]$} & {$[0.160]$} & [0.380] & {$[0.134]$} & [0.134] & [0.303] & {$[0.254]$} \\
\hline \multirow[t]{2}{*}{ Constant } & -1.997 & $8.090^{* * *}$ & $2.948^{* * *}$ & 1.603 & $1.367^{*}$ & $2.635^{* *}$ & $2.833^{* * *}$ & $5.202^{* * *}$ & -0.187 & $3.911^{* * *}$ \\
\hline & [3.124] & {$[1.896]$} & [0.562] & [1.528] & {$[0.666]$} & {$[0.840]$} & {$[0.478]$} & {$[0.442]$} & [0.950] & {$[0.616]$} \\
\hline \multirow[t]{2}{*}{ R-squared } & 0.687 & 0.078 & 0.937 & 0.740 & 0.952 & 0.768 & 0.929 & 0.863 & 0.943 & 0.876 \\
\hline & GA & $\mathrm{HI}$ & $\mathrm{ID}$ & IL & IN & IA & KS & KY & LA & ME \\
\hline Ul based & $1.692^{* * *}$ & $1.719^{* * *}$ & $0.891^{* * *}$ & $1.588^{* *}$ & $1.827^{* * *}$ & $1.611^{* *}$ & $1.346^{* * *}$ & $1.862^{* * *}$ & 1.013 & $0.883^{* * *}$ \\
\hline Unemp. R & {$[0.185]$} & {$[0.414]$} & [0.163] & {$[0.590]$} & {$[0.265]$} & {$[0.472]$} & {$[0.087]$} & {$[0.347]$} & [0.587] & [0.189] \\
\hline \multirow[t]{2}{*}{ Constant } & $2.216^{* * *}$ & 0.686 & $2.447^{* *}$ & 0.542 & $2.469^{* *}$ & 0.628 & $0.936^{* * *}$ & -1.007 & $4.331^{*}$ & $3.400^{* *}$ \\
\hline & {$[0.491]$} & [1.423] & [0.783] & [2.637] & {$[0.846]$} & {$[1.421]$} & {$[0.225]$} & [1.533] & [1.858] & [0.895] \\
\hline \multirow[t]{2}{*}{ R-squared } & 0.944 & 0.775 & 0.857 & 0.591 & 0.905 & 0.700 & 0.979 & 0.852 & 0.373 & 0.813 \\
\hline & $\mathrm{MD}$ & MA & $\mathrm{Ml}$ & MN & MS & $\mathrm{MO}$ & MT & NE & NV & $\mathrm{NH}$ \\
\hline Ul based & $0.930^{* *}$ & $1.717^{* * *}$ & $1.421^{* *}$ & $1.603^{* * *}$ & $1.357^{* * *}$ & $2.188^{* * *}$ & $1.336^{* *}$ & $1.407^{* *}$ & $1.551^{* * *}$ & $1.819^{* * *}$ \\
\hline Unemp. R & {$[0.288]$} & {$[0.184]$} & {$[0.424]$} & [0.198] & [0.259] & {$[0.461]$} & {$[0.425]$} & {$[0.503]$} & {$[0.251]$} & {$[0.285]$} \\
\hline \multirow[t]{2}{*}{ Constant } & $3.652^{* *}$ & 0.57 & 2.12 & 0.965 & $2.981^{* *}$ & -1.441 & 0.587 & 0.975 & 1.622 & 1.259 \\
\hline & {$[0.936]$} & {$[0.711]$} & {$[2.571]$} & [0.592] & {$[0.974]$} & [1.696] & [1.817] & {$[1.018]$} & [0.917] & {$[0.641]$} \\
\hline \multirow[t]{2}{*}{ R-squared } & 0.676 & 0.946 & 0.692 & 0.929 & 0.846 & 0.819 & 0.665 & 0.610 & 0.884 & 0.891 \\
\hline & NJ & NM & NY & NC & ND & $\mathrm{OH}$ & OK & OR & PA & $\mathrm{Rl}$ \\
\hline Ul based & $1.635^{* * *}$ & $1.148^{* * *}$ & $1.241^{* * *}$ & $1.488^{* * *}$ & 0.738 & $1.583^{* * *}$ & $1.352^{* * *}$ & $1.320^{* * *}$ & $1.199^{* *}$ & 1.445 \\
\hline Unemp. R & {$[0.268]$} & {$[0.196]$} & {$[0.224]$} & {$[0.196]$} & {$[0.606]$} & {$[0.291]$} & {$[0.188]$} & {$[0.115]$} & {$[0.403]$} & {$[0.724]$} \\
\hline \multirow[t]{2}{*}{ Constant } & 0.295 & $4.171^{* * *}$ & $3.146^{* *}$ & $1.986^{* *}$ & 2.222 & 2.186 & $1.868^{* * *}$ & $1.791^{* *}$ & 1.891 & -0.371 \\
\hline & [1.313] & {$[0.607]$} & [0.944] & {$[0.600]$} & [1.946] & [1.148] & {$[0.401]$} & {$[0.604]$} & {$[2.136]$} & [3.987] \\
\hline
\end{tabular}


Table 11 Coefficients of state-by-state regression of UI- based unemployment rates on BLS state unemployment rates

\begin{tabular}{|c|c|c|c|c|c|c|c|c|c|c|c|}
\hline \multirow[t]{2}{*}{ R-squared } & 0.881 & 0.873 & 0.860 & 0.920 & 0.229 & 0.855 & 0.912 & 0.963 & 0.639 & 0.443 & \\
\hline & SC & SD & TN & TX & UT & VT & VA & WA & W & WI & WY \\
\hline Ul based & $1.409^{* * *}$ & 0.973 & $2.005^{* *}$ & $2.306^{* * *}$ & $1.513^{* * *}$ & $1.171^{* * *}$ & 0.456 & $0.882^{* *}$ & $2.288^{* * *}$ & $1.581^{* * *}$ & $1.181^{* * *}$ \\
\hline Unemp. R & [0.172] & [1.348] & {$[0.715]$} & {$[0.410]$} & [0.332] & [0.093] & [0.319] & {$[0.301]$} & {$[0.147]$} & {$[0.261]$} & {$[0.161]$} \\
\hline \multirow[t]{2}{*}{ Constant } & $2.424^{* *}$ & 2.098 & 0.01 & $2.171^{* *}$ & 1.153 & $1.284^{* *}$ & $4.243^{* * *}$ & $4.094^{* *}$ & $-2.750^{* *}$ & 0.036 & $1.810^{* * *}$ \\
\hline & {$[0.607]$} & [2.777] & [2.733] & {$[0.587]$} & [1.054] & {$[0.420]$} & {$[1.043]$} & [1.578] & {$[0.760]$} & [1.104] & {$[0.314]$} \\
\hline R-squared & 0.931 & 0.094 & 0.612 & 0.863 & 0.806 & 0.970 & 0.290 & 0.633 & 0.980 & 0.880 & 0.915 \\
\hline
\end{tabular}




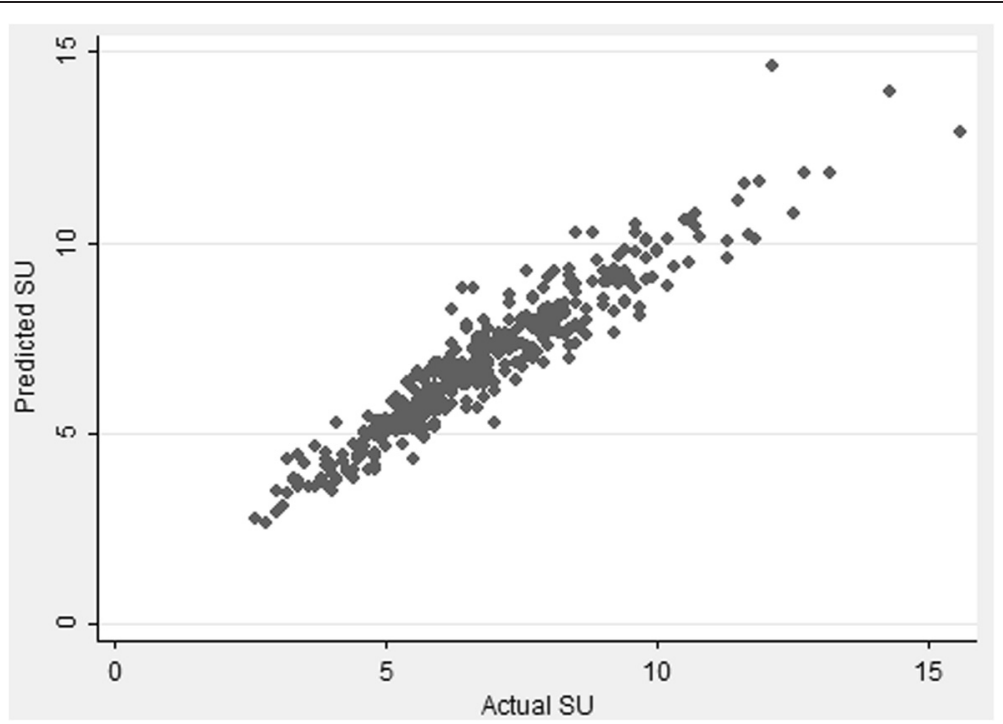

Fig. 3 Scatter plot of actual CPS-based state unemployment rates and the predicted CPS-based rates based on the Ul-based rates

\section{Appendix C: Tests for different $\beta$ across race and joint significance of $\beta$ at different potential experience within each race}

The upper panel of Table 12 reports F-statistics and p-values for the F-tests for the following null hypothesis: $\beta_{(t-y), b}=\beta_{(t-y), w}$. I conducted this test for each potential experience group and for the four regressions reported in Table 6 . The differences across race are mostly statistically insignificant, probably due to the small sample size and the large standard errors.

The lower panel of Table 12 reports F-statistics and p-values for the F-tests of joint significance of $\beta_{(t-y), w}$ and $\beta_{(t-y), b}$ in each regression. Since the initial impact is strong for blacks, $\beta_{(t-y), b}$ are jointly significant, while $\beta_{(t-y), w}$ is only marginally significant for men and insignificant for women.

Table 12 Test statistics for different $\beta$ across race and joint significance of $\beta$ at different potential experience within each race

\begin{tabular}{lllll}
\hline & Men, OLS & Women, OLS & Men, IV & Women, IV \\
\hline Tests for different $\beta$ between black and whites & & & & \\
Potential experience 1-3 years & $0.28(0.59)$ & $6.30(0.01)$ & $1.20(0.27)$ & $3.43(0.06)$ \\
Potential experience 4-6 years & $0.03(0.86)$ & $1.13(0.29)$ & $1.75(0.19)$ & $0.65(0.42)$ \\
Potential experience 7-9 years & $1.02(0.31)$ & $0.25(0.61)$ & $0.80(0.37)$ & $0.09(0.76)$ \\
Potential experience 10-12 years & $3.35(0.07)$ & $0.15(0.70)$ & $0.01(0.93)$ & $2.61(0.11)$ \\
Joint significance of $\beta$ for whites & $1.77(0.13)$ & $0.58(0.68)$ & $2.30(0.06)$ & $0.32(0.86)$ \\
Joint significance of $\beta$ for African Americans & $4.01(0.00)$ & $3.61(0.01)$ & $2.27(0.06)$ & $3.29(0.01)$ \\
\hline
\end{tabular}

Note: F-statistics are listed, and p-values are in the parenthesis below the F-statistics 


\section{Abbreviations}

AFQT: Armed forces qualification test; CPS: Current population survey; NLSY: National longitudinal survey of youth; UI: Unemployment insurance.

\section{Competing interests}

The IZA Journal of Labor Economics is committed to the IZA Guiding Principles of Research Integrity. The author declares that he has observed these principles.

\section{Acknowledgments}

This study was funded by the Japan Society for the Promotion of Science (grant number 15K17072). I would like to thank Janet Currie and Till von Wachter for their helpful suggestions on earlier draft. I also appreciate the valuable comments from the editor and three anonymous reviewers, Brendan O'Flaherty, Claudia Olivetti, Tomohiro Machikita, and participants of Applied Micro Lunch Seminar at Columbia University. Access to the geo-code data of NLSY79 requires an approval from the Bureau of Labor Statistics and is limited to researchers located in the United States. All the data analyses were conducted when the author was at Columbia University.

Responsible editor: Joni Hersch.

Received: 11 August 2015 Accepted: 25 November 2015

Published online: 10 December 2015

\section{References}

Altonji JG, Blank RM (1999) Race and gender in the labor market. Handbook of Labor Economics vol.3, Ch48

Beaudry P, DiNardo J (1991) The effect of implicit contracts on the movement of wages over the business cycle: evidence form micro data. J Polit Econ 99(4):665-688

Barr A, Turner S (2015) Out of work and into school: labor market policies and college enrollment during the Great Recession. J Public Econ 124:63-73

Betts J, McFarland L (1995) Safe port in a storm: the impact of labor market conditions on community college enrollments. J Hum Resour 30:741-765

Brunner B, Kuhn A (2014) The impact of labor market entry conditions on initial job assignment and wages. J Popul Econ 27:705-738

Card D, Lemieux T (2000) Dropout and enrollment trends in the post-war period: what went wrong in the 1970s? Working Paper no. 7658. National Bureau of Economic Research, Cambridge

Clark K, Summers LH (1981) Demographic differences in cyclical employment variation. J Hum Resour 16(1):61-79

Cockx B, Ghirelli C (2015) Scars of recessions in a rigid labor market, IZA Discussion Paper No. 8889

Cutler DM, Katz L (1991) Macroeconomic performance of the disadvantaged. Brook Pap Econ Act 2:285-239

Fernández-Kranz D, Rodríguez-Planas N (2015) The perfect storm: graduating in a recession in a segmented labor market, Presentation at SOLE/EALE $4^{\text {th }}$ World Meeting

Devereux PJ (2004) Cyclical quality adjustment in the labor market. South Econ J 70(3):600-615

Genda Y, Kondo A, Ohta S (2010) Long term effects of a recession at entry in Japan and the United States. J Hum Resour 45(1):157-196

Gregg P (2001) The impact of youth unemployment on adult unemployment in the NCDS. Econ J 111:F626-F653

Hershbein BJ (2012) Graduating high school in a recession: work, education, and home production. B E J Econom Anal Policy 12:1-32

Hines JR Jr, Hoynes H, Krueger AB (2001) Another look at whether a rising tide lifts all boats, Working Paper, no. 8412. National Bureau of Economic Research, Cambridge

Hoynes H, Miller DL, Schaller J (2012) Who suffers during recessions? J Econ Perspect 26(3):27-48

Kahn LB (2010) The long-term labor market consequences of graduating college in a bad economy. Labour Econ 17(2): 303-316

Kondo A (2012) Gender-specific labor market conditions and family formation. J Popul Econ 25:151-174

Maclean J (2014) Does leaving school in an economic downturn impact access to employer-sponsored health insurance? IZA J Labor Policy 3:19

Maclean J (2015) The lasting effects of leaving school in an economic downturn on alcohol use. Ind Labor Relat Rev 68:120-152

Maclean J, Covington R, Kessler AS (2015) Labor market conditions at school-leaving: long-run effects on marriage and fertility. Contemp Econ Policy, forth coming

Neumark D (2002) Youth labor markets in the United States: shopping around vs. staying put. Rev Econ Stat 84(3):462-482

Okun A (1973) Upward mobility in a high-pressure economy. Brook Pap Econ Act 1973(1):207-261

Oreopoulos P, von Wachter T, Heisz A (2012) The short-and long-term career effects of graduating in a recession. Am Econ J Appl Econ 4(1):1-29

Raaum O, Røed K (2006) Do business cycle conditions at the time of labor market entry affect future employment prospects? Rev Econ Stat 88(2):193-210

Speer JD (2015) Wages, hours, and the school-to-work transition: the consequences of leaving school in a recession for less-educated men. B E J Econom Anal Policy, forth coming

Wozniak A (2010) Are College graduates more responsive to distant labor market opportunities? J Hum Resour 45(4): 944-970 